\title{
La Gramatica de la Lengua Vulgar de España (Lovaina, 1559), ¿anónima?
}

\author{
The Gramatica de la Lengua Vulgar de España (Louvain, 1559), \\ anonymous?
}

\author{
Miquel Almenara \\ miquel.almenara@gmail.com \\ ORCID iD: https://orcid.org/0000-0001-9164-0190 \\ Concepción Ferragut \\ Universitat de València \\ concepcion.ferragut@uv.es \\ ORCID iD: https://orcid.org/0000-0001-8122-4775 \\ Ferran Grau \\ Universitat de València \\ ferran.grau@uv.es \\ ORCID iD: https://orcid.org/0000-0003-2761-5470
}

RESUMEN: Para demostrar la autoría de la Gramatica de la Lengua Vulgar de España nos basamos en los siguientes puntos: el uso en El Concejo $i$ Consejeros del Príncipe (Amberes, 1559) de Furio Ceriol de las normas ortográficas propuestas en la Gramatica; la denominación de la lengua castellana o española como lengua 'vulgar' de España, en la misma obra de Ceriol; las ideas lingüísticas contenidas en la Gramatica y en Bononia de Ceriol; la organización retórica de la Gramatica; y, en último lugar, la comparación entre el poema dedicatorio en la Gramatica y los de las obras de Furio Ceriol.

Palabras clave: Furio Ceriol, Gramática, Flandes, imprenta, autoría.

ABSTRACT: To demonstrate the authorship of the Gramatica de la Lengua Vulgar de España, we rely on the following points: the use in Furio Ceriol's El Concejo i Consejeros del Principe (Antwert, 1559) of the orthographic rules proposed in the Gramatica; the denomination of the Castilian or Spanish language as the 'vulgar' language of Spain, in the same work of Ceriol; the linguistic ideas contained in the Gramatica and in Ceriol's Bononia; the rhetorical organization of the Gramatica; and finally, the comparison between the dedicatory poem in the Gramatica and these ones in the works of Furio Ceriol.

Keywords: Furio Ceriol, Grammar, Flanders, printing, authorship. 


\section{El LIBRO EN CASTELLANO EN FLANDES}

Es posible afirmar sin demasiado margen de error que El Concejo i Consejeros del Principe de Fadrique Furio Ceriol $^{1}$, salido de las prensas de la viuda de Martín Nucio en 1559 en Amberes, constituye una notable singularidad en cuanto a la ortografía utilizada, ortografía que no aparece en los libros impresos en castellano en Flandes, especialmente entre 1558 y 1560 y que, como demostraremos más adelante, se corresponde, precisamente, con la ortografía propuesta en la Gramatica de la Lengua Vulgar de España, imprimida en Lovaina en el mismo 1559.

La justificación de una afirmación tan contundente se fundamenta en el examen de tres aspectos lo suficientemente característicos de esta ortografía: el destierro de la $y$ del alfabeto y, por consiguiente, de su uso en la escritura; la escrupulosa distinción entre $u$ consonántica (uve) y $u$ vocálica, una práctica que no se fijará hasta el siglo XVIII (Echenique y Martínez Alcalde, 2013: 85)²; y, por último, la utilización de la diéresis sobre la $i$ para indicar hiato. Estos elementos suficientemente significativos solamente aparecen utilizados de forma sistemática en la Gramatica de la Lengua Vulgar de España y en El Concejo, i Consejeros del Principe.

La existencia de una industria editorial en castellano en Flandes exigía la presencia de conocedores de la lengua y correctores expertos, y en los casos en que fuera posible o así lo estableciera el contrato de publicación, la intervención del autor en persona en la corrección de las pruebas de imprenta; no obstante, el proceso de impresión era complejo y normalmente entre el manuscrito del autor y el impreso se interponía la copia de un amanuense para la imprenta, corregida a su vez por el autor (Andrés et al., 2000: 45) ${ }^{3}$. Son escasos los nombres conocidos de estos profesionales, por lo que la información sobre la actividad como corrector de Juan Martín Cordero constituye una excepción (Martos, 2015). Sin embargo, y en relación con la imprenta de Nucio, identificamos dos modelos ortográficos,

\footnotetext{
${ }^{1}$ Escribimos el sobrenombre Furio sin acento, pues nuestro autor lo hizo derivar de los Furii romanos, y en ningún caso el apellido Furió perteneció a su familia. Así, adoptó el praenomen Fridericus y el nomen romano Furius en sustitución de Miquel Joan, su nombre de pila, latinizó su nomen nativo propio, Ceriol, en Caeriolanus y añadió, como era habitual, el gentilicio Valentinus, por ser natural de Valencia. No obstante, hemos respetado la tilde cuando citamos textos en los que se escribe con ella, aunque la hemos eliminado cuando aparece como autor en la bibliografía.

${ }^{2}$ Agradecemos a la profesora Martínez Alcalde las observaciones e indicaciones bibliográficas al presente trabajo.

${ }^{3}$ Moll (2000: 125-126) da detalles del proceso seguido para la impresión del Compendio historial de las chronicas y vniversal historia de todos los reynos d'España ... (Impreso en Anveres. Por Christophoro Plantino, prototypographo de la Catholica Magestad, à costa d'el autor, con los priuilegios al principio notados), cuyos dos primeros tomos llevan la fecha de 1571 y el tercero de 1572, de Esteban de Garibay y Zamalloa, quien hizo cuatro copias en letra francesa de su original y "así por la letra francesa imprimían y por mi original lo corregían dos corretores para esto diputados, los quales hacían la primera y segunda prueba e yo la tercera, para sola la continuación de las materias, por no haber peor corretor que el autor para todo lo demás, y la quarta ellos, y con esta diligencia se imprimía después".
} 
el primero ${ }^{4}$, utilizado desde los años 40 del siglo XVI, que tiene su base en el uso de los autores en sus originales y de las imprentas de la península, y el segundo, de uso no generalizado, que aparece por primera vez en 1552 en la edición de El felicissimo viaje de Calvete de la Estrella, y cuyas características más visibles, como la utilización del apóstrofo cuando se elide la $e$ en la preposición $d e$, en el artículo de las palabras que empiezan por $a$, el empleo de la tilde sobre la preposición à, o el de un acento diacrítico en los verbos (Cordero, 1556: 116r), aparecen vinculadas a la intervención de Juan Martín Cordero en las ediciones bajo su responsabilidad ${ }^{5}$.

La singularidad ortográfica de El Concejo, coincidente en todos sus aspectos con la singularidad gramatical de la Gramatica de la Lengua Vulgar de España, exigía que la corrección de imprenta fuese extremadamente meticulosa, sobre todo en cuanto al uso diferenciado de $u / v$, ya que este era atípico y absolutamente en contra de la práctica habitual, que utilizaba de manera mecánica $v$ para los inicios de palabra y $u$ para los interiores. De hecho, se hallan más 'erratas' a este respecto en la Gramatica que en El Concejo, lo que indica, con toda probabilidad, la necesaria presencia y corrección por parte del autor, y una mayor meticulosidad en esta segunda obra. Sabemos, gracias al testimonio que nos ofrece la carta al lector, añadida al final del texto, de sus Institutionum Rhetoricarum libri III, publicados en Lovaina en 1554, que Ceriol se encargaba de la corrección de las pruebas de imprenta de sus obras y que era, además, extremadamente meticuloso:

Nec per ualetudinem mihi nec per otium licuit eorum quae imprimebantur correctioni interesse. Hic factum est ut liber hic minus quam uellem castigate imprimeretur. Quod autem "Epistola nuncupatoria" in aliis exemplaribus satis correcta sit, in aliis mendosa reperiatur, illud in causa fuit, quod cum exemplum primae impressionis ad me famulus ad multam noctem detulisset, emendaui, nec ad typographum, quoniam instabat prima post mediam noctem hora, remisi (Institutiones, s. p. [281]).

\footnotetext{
${ }^{4}$ Esta ortografía, la más ampliamente utilizada, es fácil de identificar para nuestros propósitos: uso de la $y$ como conjunción copulativa y en diptongos decrecientes, ausencia de $h$ en las formas del verbo haber y ausencia de apóstrofos.

5 Por ejemplo, constatamos la ausencia de la ortografía vinculada a Cordero en la imprenta de la viuda de Nucio entre 1558 y 1560 . Vuelve a aparecer en esta imprenta en 1561, en la reimpresión de su traducción de la Historia de Eutropio. Fuera de esta, aparece su ortografía en la Summa de la doctrina christiana de Canisius, traducida por Cordero e impresa por Guillaume Simon en 1558; en 1559 en el Tratado de las fuentes azedas ... de Espa, imprimido en Amberes por Jean Bellère, y en 1560 en Los vivos retratos de todos los Emperadores de Goltzius, traducido por Cordero e imprimido en Amberes por Egide Coppens. El resto de impresiones consultadas, tomando como guía el catálogo de Peeters-Fontainas (1965: 818-820), sigue la ortografía más generalizada, con la excepción de El Concejo, $i$ Consejeros del Principe de Furio. Por su parte, la imprenta de Gravio, en Lovaina, solo imprime libros relacionados con el aprendizaje de la lengua, como gramáticas o vocabularios (Swiggers, 2006: 165-167); para un estudio de sus ediciones y tranformaciones véase Acero (2008) y Pablo (2010: I 47-198 y II 202-312).
} 
[Ni por una enfermedad ni por trabajo pude estar presente en la corrección de las pruebas de imprenta. Y el resultado ha sido que este libro se ha imprimido menos corregido de lo que yo deseaba. Y en cuanto a que la "Epístola nuncupatoria" aparezca en unos ejemplares con bastantes correcciones y que en otros esté plagado de erratas, se debe a que, tras haberme traído el asistente de la imprenta la muestra de la primera tirada de prueba bien entrada la noche, me puse a corregir, pero no se lo remití al tipógrafo por ser ya de madrugada] ${ }^{6}$.

Furio, como vemos, no ha podido ocuparse personalmente de las correcciones, por hallarse enfermo o no disponer de tiempo suficiente; esta epístola nuncupatoria, impresa después que el libro en sí (de hecho, en la edición no se indica el número de página, a diferencia del resto, y está añadida al final de todo), nos presenta la premura y el poco tiempo disponible para realizar las correcciones oportunas, tomándose el impresor el cuidado de enviar a Furio las pruebas. Vemos a un Furio preocupado y atento al texto que sacará a luz el impresor. Y esto nos lleva a otra conclusión: no es posible imprimir un texto de las características de El Concejo sin la intervención y corrección de su autor.

\section{ARGUMENTOS ORTOGRÁFICOS}

Previamente al análisis de los argumentos formales y de estilo, es importante señalar que para un conocedor de la obra y de la trayectoria personal de Furio no resulta sorprendente, a priori, que este redactara un manual de gramática, pues ello confirmaría la coherencia absoluta del pensamiento y el carácter del valenciano, basado en un constante equilibrio entre la teoría y la práctica; por ejemplo, $E l$ Concejo, desde el punto de vista formal, está construido según el aparato teórico de las Institutiones Rhetoricae, como creemos haber podido demostrar en trabajos anteriores (Ferragut y Grau, 2016); del mismo modo, el modelo teórico de consejero propuesto en $\mathrm{El}$ Concejo encuentra su praxis en la propia persona de Furio, encarnación ideal del consejero perfecto, como declara en su Petición a Felipe $I I^{7}$ (7 de octubre de 1581) solicitando el cargo de vicecanciller de Aragón ${ }^{8}$.

En este contexto, pues, no sería extraño que la Gramatica de la Lengua Vulgar de España, especialmente el libro I, dedicado a la ortografía, constituyera el marco teórico planificado por Furio para dar carta de naturaleza a su praxis escrituraria.

\footnotetext{
${ }^{6}$ Todas las traducciones de las Institutiones son nuestras.

${ }^{7}$ En efecto, algunos de estos presupuestos, como el mérito personal, el talento, la poliglosia, etc., virtudes que ha de poseer el consejero, se hallan entre los ofrecimientos de Furio al rey Felipe II.

${ }^{8}$ Se conservan dos autógrafos, uno en el Instituto Valencia de Don Juan de Madrid (IVDJ, Envío 93, doc. 164), y otro en el Archivo Zabálburu (carpeta 219 - 19 [Furió]), también en Madrid; véase Méchoulan (Furio Ceriol, 1993: 91-95), quien, no obstante, no ha podido consultar los originales.
} 
Existen unas características formales y de estilo que suponen una constante en la obra de Furio, demostrando cómo el valenciano crea, si no un lenguaje propio, sí una ortografía propia y unos rasgos estilísticos y organizativos peculiares e identificables. De las características formales destaca, en primer lugar, como hemos dicho, su ortografía, realmente singular, que presenta algunos rasgos únicos e inconfundibles, y que Furio mantendrá de forma constante y sistemática en todos sus escritos durante toda su vida, no sólo en su obra, podríamos decir, más pública, sino también en sus informes y cartas privadas conocidos hasta el momento. Igualmente, nuestro autor es muy consciente de su forma particular de escribir y de su "singular ortografía", la cual se expone desde el punto de vista teórico en la Gramatica, y se pone en práctica en El Concejo $^{10}$ y en el resto de escritos no publicados por Furio como, por citar un ejemplo, la Petición a Felipe II (7 de octubre de 1581) convirtiéndose esta ortografía en un criterio, precisamente, para identificar autógrafos y autorías ${ }^{11}$.

Para constatar esta realidad, realizaremos un breve análisis de los rasgos más originales de la Gramatica, que se centran precisamente en la teoría ortográfica, para luego comprobar la presencia de los mismos en la obra de Furio, no sin antes remarcar que la Gramatica es original no solo en el planteamiento de unas reglas ortográficas determinadas, sino también en otros aspectos, como la nomenclatura de ciertas consonantes ${ }^{12}$. El punto de partida, no obstante, reside en un aspecto

9 Estas peculiaridades ortográficas son puestas de manifiesto por el mismo Furio en su Sobre los títulos y cortesías en el scriuir (1583): "Illmo señor: El Auerseme encogido vn neruio de la mano derecha q muy poco a poco se me va alargando la cura q le hago de contino, el dolor que a ratos me causa q a gran pena puedo scriuir tres renglones sin que se me abra todo el braço, y a causa de mi diferente ortografia con que scribo no puedo ni quiero aprouecharme de mano agena, por estas y tan justas causas no he podido seruir a V.S. con lo que me manda le scribiese cerca del vso o abuso comun de los titulos desta españa" (Lagomarsino, 1979: 97). Curiosamente, y a pesar de que Lagomarsino (1979: 96-97) considera el hológrafo una de las dos copias existentes de este texto (British Library Ms. Additional 28.371, fol 60r-62v y 33r-38r), no podemos apreciar aquí las singularidades de su diferente ortografía, por lo que, en consecuencia, debemos considerar ambos textos copias del original autógrafo, actualmente desaparecido.

${ }^{10}$ Quisiéramos hacer constar que ninguna de las ediciones modernas de la obra ha respetado en su totalidad la ortografía de la primera edición.

11 Lagomarsino (1978: 95, n. 34) utiliza precisamente este criterio para atribuir a Furio Ceriol los Auisos acerca de los Estados Baxos, manuscrito autógrafo original conservado en el Archivo General de Simancas, Estado, leg. 549, núm. 129: "En especial subrayamos la utilización de la vocal «i» en lugar de «y», el muy frecuente uso de comas y de frases parentéticas, y una organización altamente esquematizada", rasgos todos ellos presentes en El Concejo. Sin embargo, y de manera sorprendente, la ausencia de estos mismos rasgos no hace rechazar a Lagomarsino (1979: 97) el carácter "hológrafo" del Sobre los títulos y cortesías en el scriuir de nuestro autor.

12 En efecto, en su clasificación de las consonantes "mediovocales", según terminología del autor, que incluye las consonantes líquidas, nasales y sibilantes, emplea una curiosa y descriptiva terminología: perrinas $(r)$, culebrinas $(s, z, c ̧, x)$, torinas $(m, n, \tilde{n})$. La denominación de la $r$ como "canina" se ve en Persio (sat 1, 109.110: sonat hic de nare canina / littera), pero ni la clasificación ni la nomenclatura es utilizada por los gramáticos antiguos, como también observa Swiggers (2006: 
fundamental, el término preciso para denominar la lengua objeto de estudio, que no hallamos en ninguna de las reflexiones sobre la lengua ni en ninguna de las gramáticas existentes: Gramatica de la lengua Castellana, de Antonio de Nebrija (Salamanca, 1492), Vtil y breue institution para aprender los principios y fundamentos de la lengua hespañola, anónima (Lovaina, 1555), La manera de escrevir en Castellano de Juan Martín Cordero (Amberes, 1556), y Gramatica Castellana de Cristóbal de Villalón (Amberes, 1558).

\section{La denominación de la lengua: La lengua Vulgar de España}

Como puede apreciarse fácilmente en los títulos mismos de estas obras, lo que para Nebrija, Cordero y Villalón es "lengua castellana" y para el anónimo autor de la Vtil y breue es "lengua hespañola", en la Gramatica, cuyo autor conoce y rechaza ambas denominaciones, recibe el nombre propio de "Lengua Vulgar de España”, indicándose que es una terminología novedosa:

El quarto lenguaje, es aquel, que io nuevamente llamo, Lengua Vulgar de España, porque se habla, i entiende en toda ella generalmente [...] A esta, que io nombro Vulgar, algunos la llamaron lengua Española [...] Otros la llamaron Castellana... (Gramatica [Balbín y Roldán, 1966: 6-7]) ${ }^{13}$.

Es importante señalar que esta denominación no aparecerá tampoco en ninguna otra gramática posterior ${ }^{14}$, ni será utilizada por autor alguno en ningún otro contexto en tanto que nombre propio de la lengua, con una única excepción: el tratado de ciencia política escrito por Fadrique Furio Ceriol, El Concejo, i Consejeros del Principe, editado por primera vez en 1559, en Amberes, en casa de la viuda de Martín Nucio. Es difícil negar, cuando menos, la existencia de una conexión entre ambas obras, las únicas en emplear una denominación que Furio, si no es él mismo el creador, hace suya empleándola en las dos únicas ocasiones en las que en El Concejo, $i$ Consejeros del Principe menciona la lengua española. La primera de ellas se encuentra en el prólogo de la obra, cuando Furio habla de la dualidad del gobernante:

206, nota 92), a pesar de la afirmación de Alonso (1949: 33) de que dicha terminología hunde su origen en Varrón (Maquieira, 2006: 377). Curiosamente, encontramos una terminología similar un año más tarde en la gramática francesa de A. Matthieu Second deuis et principal apropos de la langue francoyse (Paris, 1560), que emplea los términos "lettre du chien" y "lettre serpentine" (Kukenheim, 1974: 78). También son originales la denominación de $x$ como "ixe", $c$ como "cace", $g$ como "gage", y la $h$ como "ha".

13 Citamos las páginas según la edición facsímil de Balbín y Roldán (1966), sin embargo, nos hemos servido del ejemplar de la Gramatica disponible en la biblioteca digital de la Bayerische StaatsBibliothek.

${ }^{14}$ Sobre el nombre de la lengua todavía es fundamental el estudio de Amado Alonso (1958). 
Todo Principe es compuesto casi de dos personas, la una es obra salida de manos de la Naturaleza, en quanto se le comunica a un mesmo ser con todos los otros hombres. La otra es merced de la Fortuna, i favor del Cielo, hecha para govierno i amparo del bien publico, a cuia causa la nombramos persona publica; i restriñendole este su nombre de una tan grande generalidad en mas particular, muchos de muchas maneras la llamaron, i en lengua vulgar de España lo más ordinario es nombrarla Rei. Io la llamo Principe... (El Concejo, "Prólogo", s. p. [1-2]; Furio, 1996: 85).

La segunda tiene lugar más adelante, cuando al hilo de la explicación de la novena calidad en el alma del consejero, elogia el comportamiento de Q. Fabio Máximo ante Aníbal en la batalla de Cannas mencionando unos versos de Enio:

I assi le loa altamente el gran poeta Enio en unos versos, que (por ser dinos de estar escritos en letras de oro por los aposentos de los Principes) me esforçaré en vertirlos en lengua Vulgar de España lo menos mal que pudiere (El Concejo, f. 38v-39r; Furio, 1996: 111).

Podemos considerar, pues, esta singular terminología empleada por Furio en $\mathrm{El}$ Concejo como el primer elemento, no sin importancia, que vincula al valenciano con la anónima Gramatica. La prueba decisiva será, en nuestra opinión, constatar si la teoría ortográfica de la Gramatica se ve aplicada en el famoso tratado de Furio, su única obra impresa no escrita en latín, y en el resto de su obra manuscrita.

\section{La Gramatica frente a algunas gramáticas anteriores}

Como ya hemos dicho, la Gramatica dedica el primero de sus dos libros a la ortografía, en la que destacan algunos aspectos que la diferencian de otras gramáticas precedentes, en concreto, el tratamiento de la $y$, de la cedilla, de la diéresis para representar el hiato y, en último lugar, y especialmente importante, el uso de la $u / v$ para representar sonidos diferentes. Vamos ahora a ver la teoría de cuatro gramáticas sobre estos cuatro aspectos ${ }^{15}$ :

1. Con respecto a la $y$, la Gramatica defiende su destierro absoluto ${ }^{16}$ :

Lo qual me da ocasion de echar fuera de la lengua Vulgar la $-y$, Griega; porque suena en Griego, i en latín, bien pronunciada, lo mesmo que la $-u$; i

15 Aunque Maquieira (2006: 379-386) compara extensamente aspectos de clasificación y pronunciación de las 'letras' en las gramáticas del español del s. XVI, no alude a la propuesta del autor de la Gramatica de desterrar la y de la escritura del castellano ni a la diferenciación gráfica entre vocal $u$ y consonante $v$.

16 Ya Prisciano (Grammatici Latini, vol. 1, p. 9, 1. 9, Keil) solamente admitía su uso en la transcripción de palabras griegas. Ramus también es partidario de suprimirla en su lengua: “...ie retiens que 1'y gregois vacqueroit en nostre orthographie" (Scholae grammaticae 1559, p.14, en Kukenheim, 1974: 41-42). Las cursivas son nuestras, no así los guiones y otros símbolos. 
no lo que nuestra, $i$, como nosotros della abusamos; mas, que segun nuestro uso sonando en todo, i por todo lo mesmo que la $-i$; es mui superflua la $-y$; de manera, que nunca me aprovecho de la $-y$, ni se debria permitir en nuestra lengua; i assi escrivo = doi, voi, soi, io; i no quiero escribir, doy, voy, soy, yo. Esta mesma escritura guardo, i se deve guardar en los nombres Griegos, i qualesquier otros peregrinos; porque escrivo $=$ Dionisio, Geronimo; i no $=$ Dionysio, Geronymo; i de la mesma manera todos los demas, que huviere (Gramatica [Balbín y Roldán, 1966: 12]).

De las gramáticas precedentes solo Nebrija descarta parcialmente la $y$, aceptándola únicamente en empleos con valor consonántico, uso que también propone Cordero para el verbo, aceptando a su vez los usos arraigados y etimológicos:

La $y$ griega tan poco io no veo de que sirve: pues que no tiene otra fuerça ni sonido que la $i$ latina: salvo si queremos usar della enlos lugares donde podria venir en duda si la $i$ es vocal o consonante. Como escriviendo raya ayo yunta: si pusiessemos $i$ latina diria otra cosa mui diversa raia. aio. iunta (Nebrija, 2011: 30; 1492: [f.10]).

La sexta cosa que se deue obseruar es, que vsamos $y$. adonde cabria muy bien la $i$ pequeña, pero esto no haze al caso, porque no es cosa que importa tanto, sino en ciertos vocablos que despues mostrarémos [sic] [...] El exemplo lo hara claro. Oya, y oia, el primer verbo son dos sylabas, pero el segundo son tres (Cordero, 1556: f. 115v y 117v).

En cambio, la Vtil y breue y Villalón aceptan su uso, incluyéndola entre las vocales:

La lengua Hespañola, tiene tantas vocales, y consonantes, y de tal figura, y potestad, como su madre la lengua Latina. [...] Quando las vocales estan aiuntadas (lo qual llaman los griegos Diphtongos), entonces tienen una propia pronunciación. De esta coniunction de vocales se hazen cinco diphtongos. El primero es en $A y$, o en $A i$ : que es todo uno. En el qual, la $A$ se pronuncia, y muy poco se hiere ô toca la y ô $i$ (Vtil y breue [Roldán, 1977: 5]).

Las vocales son çinco, $A, e, i, o, u$. Y ay otra. $y$, que llaman los Griegos ypsilon: que nosotros podremos llamar y mayor: de la qual vsamos en prinçipio de parte (Villalón [García, 1971: 63]).

2. Con respecto al uso de cedilla, la Gramatica la acepta únicamente delante de $a, o, u$ :

La ç; que llaman Cerilla, suena del modo ia dicho: [...] Iuntase tansolamente con estas tres letras $-a, o, u$, como çapato, çoçobra, çumaque. portanto, devemos condenar vna tal escritura como es esta, careçe, çertenidad, prinçipio, çierto, i otras semejantes, porque no es menester que se escriuan con Cerilla (Gramatica [Balbín y Roldán, 1966: 20]) ${ }^{17}$.

17 Nótense las "erratas" vna y escreuir, que contradicen la propia norma de la Gramatica. 
Al igual que Cordero:

...pero entiendas que dondequiera que la $c$, se junta con la $e$, ò con $i$, no es necessario notar $c$, sino $c$ solamente, porque en Español no se halla jamas otra pronunciacion con $c e$, ni con $c i$ (Cordero, 1556: f. 112v).

Nebrija, la anónima Vtil y breue y Villalón la emplean con cualquier vocal:

La $c$ tiene tres oficios: uno propio: cuando despues della se siguen $a$. $о$. $u$. como en las primeras letras destas diciones: cabra. coraçon. cuero. Tiene también dos oficios prestados: uno cuando debaxo della acostumbramos poner una señal que llaman cerilla: como en las primeras letras destas diciones: çarça: çevada (Nebrija, 2011: 30; 1492: f. 10).

Pronunciasse pues $c$ con vna çerilla de baxo, puncto, ô medio circulo, mas asperamente que la $s$, y mas delicadamente que si fuesse $z$. de manera que es media pronunciación entre las dos, y haze vn son templado de las dos, como çapato, calceus, çebollas, cepas, çenizas cineres (Vtil y breue [Roldán, 1977: 6]).

Pero es de notar, que digo que la $c$, simple tiene el mesmo sonido que la $q$, porque suele el Castellano escreuir la $c$, con vna çedilla al pie, que la haze casi z. Y ansi vsan los Castellanos escreuir çebolla, çedaço, çelestial, çelada, çelebrar (Villalón [García, 1971: 68]).

3. Por lo que se refiere al empleo de la diéresis para indicar el hiato, es este un rasgo único de la Gramatica pues, aunque los gramáticos españoles conocen este signo, raramente hablan de él y únicamente lo admiten en poesía (Kukenheim, 1974: 71). En las cuatro gramáticas que estamos comparando con la Gramatica ni se menciona; por su parte, la Gramatica indica en el capítulo de los diptongos que se ha de emplear este signo para señalar el hiato:

Quando las dos Vocales sobredichas se hallan juntas, i no hazen cuerpo, sino que cada una es por si, entonces se deven poner dos puntillos encima dellas, por quitar toda confusion; desta manera -caïda, vaïna, i assi mesmo en todos, los que fueren desta calidad (Gramatica [Balbín y Roldán, 1966: 13]).

4. En cuanto al uso de la $u / v$, Nebrija distingue entre $u$ vocal y $u$ consonante en la Gramatica Castellana y en la parte castellana del Diccionario Latino-Español (1494):

La $u$, como diximos de la $i$, tiene dos oficios: uno proprio, cuando suena por sí como vocal, assí como en las primeras letras destas diciones: uno, uso; otro prestado, cuando hiere la vocal, cual pronunciación suena en las primeras letras destas diciones: valle, vengo (Nebrija, 2011: 32; 1492: f. 11) ${ }^{18}$.

18 Hasta tal punto es frecuente en este momento la confusión de las grafías $u / v$ que la propia Gramática castellana presenta en la práctica abundantes muestras de la misma, en clara contradicción con la teoría. Como indican Galindo y Ortiz (1946: 158-159): "Nebrija en GC [Gramática 
Sin embargo, renunció a mantener en sus Reglas de Ortographia de 1517 la reforma ortográfica propuesta en la Gramática castellana de 1492, presentándola como "una simple posibilidad, muy deseable pero utópica" (Schmid, 1998: 67), quizá por resignación ${ }^{19}$, tras constatar que en esos 25 años, lejos de atenuarse, las confusiones en la ortografía castellana iban en aumento debido a los desajustes producidos por los incipientes cambios fonéticos (Schmid, 1998: 65-67).

Villalón y el autor de la Vtil y breue, al igual que Cordero, conservan el uso generalizado de la grafía $v$ tanto para $u$ vocálica como para la consonante en posición inicial, y de la grafía $u$ tanto para la vocal como para la consonante en posición interior.

En la Gramatica es sistemático el uso de la $u$ vocálica en posición inicial de palabra y de $v$ consonántica en posición interior. A este respecto dice la norma:

$\mathrm{La}-v$, que io nombre $-v e$, es (como se paresce) Consonante; i assi como le doi diferente nombre de la $-u$, Vocal; de la mesma manera la hago de figura diferenciada, para que no se confundan en la vista i parescer, pues tienen diversos cargos repartidos entre si, de manera que la Ve siempre la escrivo, i se debe escrivir desta manera $-v$; que es quando hiere alguna Vocal; i a esta causa escrivo -voluntad, variedad, advertir, escrivir; i no uoluntad, uariedad, aduertir, escriuir; i en las demas, del mesmo modo. Su pronunciacion es como en las lenguas Latina, Italiana, i Francesa (Gramatica [Balbín y Roldán, 1966: 24-25]).

Esta regla se respeta no solo en la teoría sino también en la praxis dentro de la propia Gramatica, con un uso sistemático de la misma, ya que en toda la obra solo aparecen 16 casos de $v$ por $u$ vocálica en inicio de palabra (casi siempre en vna o vn), y 13 casos de $u$ por $v$ consonántica en posición intervocálica. En todos se trata claramente de un error mecánico, pues las palabras objeto del error aparecen bien escritas en el resto del manual.

\section{La Gramatica en relación con El Concejo, i Consejeros del Principe de Furio}

Todos estos aspectos ortográficos singulares de la Gramatica son, como hemos adelantado ya, rastreables y reconocibles en El Concejo, i Consejeros del Princi-

Castellana] (cfr. 26, 3-7) y RO [Reglas de ortographia, 1517] (246, 6-13) propone u para el oficio de la u como vocal y v para la consonante. Esta regla no se cumple en la $G C$ sin duda por descuido del autor o por desidia de los impresores, acostumbrados a la mixtificación de u y v, muy corriente en la época". También Esteve (1982: 134-135) alude a esta cuestión mencionando únicamente el testimonio de Valdés a favor de la diferenciación gráfica y fonética entre $u / v$.

${ }^{19}$ Schmid (1998: 67) atribuye esa resignación al desinterés de los "príncipes del siglo" por modernizar la preceptiva ortográfica. En esa misma idea de decepción y desencanto insiste Casas (2010: 21, n. 12) al recordar cómo la pasividad de la autoridad real en materia de preceptiva gramatical hace mella en el empeño regularizador del andaluz y le mueve a mostrar su escepticismo. 
$p e$, hecho de especial relevancia, dado que ambas obras se publicaron el mismo año (1559), pero se imprimieron en dos ciudades diferentes (Lovaina y Amberes, respectivamente) por dos impresores distintos (Gravio y Nucio).

Efectivamente, en El Concejo encontramos ${ }^{20}$ :

1. Destierro de la $y$, que no aparece ni una sola $v^{2} z^{21}$, siendo sustituida en todas las posiciones por la $i$ latina en ambas obras (leies, rei, soi, io, mui...).

2. Uso de $c ̧$ ante $a, o, u$ (cabeça-pieça, çoçobra-pedaço), y de $c$ delante de $e, i$ (cierto, merced, principio).

3. Representación del hiato mediante la diéresis (dïa, rë̈r, ö̈r, ö̈do, huïda y huïr, deurïan, podïan...).

4. Respeto riguroso de $u$ vocálica y $v$ consonántica: un, una, vulgar, voluntad, variedad, conservarse, bive $e^{22}$; únicamente existen 7 casos de $u$ por $v^{23}$, y 2 de $v$ por $u$, y se deben también a un error mecánico, probablemente del cajista.

En la tabla 1 presentamos un cuadro comparativo de los paralelos ortográficos en las dos obras, indicando en la columna de la izquierda las vocales y consonantes tratadas por la Gramatica, en la central las palabras usadas en la Gramatica como ejemplo de la regla ortográfica explicada al respecto, y en la de la derecha las palabras encontradas en El Concejo que siguen al pie de la letra la teoría ortográfica de la Gramatica.

\footnotetext{
${ }^{20}$ Hay otros paralelos entre ambas obras, como la simplificación del grupo consonántico -gn-, pero nos ceñimos únicamente a los más significativos.

${ }^{21}$ No así en las ediciones posteriores de este texto, sobre todo en las recientes.

22 También el paradigma del verbo 'bivir', en la Gramatica [Balbín y Roldán, 1966: 51].

${ }^{23}$ Si contamos, además, un caso en la portada, otro al final, en el privilegio, y consideramos erróneas las formas deurian $(2 \mathrm{v}, 35 \mathrm{v})$, haura $(22 \mathrm{v})$, deuria $(47 \mathrm{v})$, en total serían 13 casos.
} 


\begin{tabular}{|c|c|c|c|}
\hline \multicolumn{4}{|c|}{ Coincidencias ortográficas } \\
\hline & & $\begin{array}{l}\text { Gramatica (la / separa la gra- } \\
\text { fía aconsejada de la grafía a } \\
\text { evitar) }\end{array}$ & $\begin{array}{l}\text { El Concejo, } i \text { Consejeros del } \\
\text { Principe }\end{array}$ \\
\hline vocales i/y & & $\begin{array}{l}\text { lei, rei, io, doi, voi, soi / doy, } \\
\text { voy, soy } \\
\text { mui }\end{array}$ & $\begin{array}{l}\text { leies, rei, io, soi, hoi } \\
\text { aiuda, mui }\end{array}$ \\
\hline hiatos & & $\begin{array}{l}\text { mïa, porfia, dïa, desvïa } \\
\text { reïr, oïdo, oïr, huïda }\end{array}$ & $\begin{array}{l}\text { deurïan, podïan, ternïamos, } \\
\text { dïa, lastimarïan, reïr, oïdo, } \\
\text { oïr, huïr }\end{array}$ \\
\hline \multicolumn{4}{|c|}{$\begin{array}{l}\text { consonantes mediovo- } \\
\text { cales (líquidas, sibilan- } \\
\text { tes, nasales) }\end{array}$} \\
\hline perrina & $\mathrm{r}$ & $\begin{array}{l}\text { razon / rrazon; rei / rrei; } \\
\text { honra / honrra }\end{array}$ & razon, rei, honra \\
\hline \multirow[t]{4}{*}{ culebrinas } & $\mathrm{s}$ & causa, espero / spero & causa, esperança, espiritu \\
\hline & $\mathrm{Z}$ & zelo, doze, luz, nariz & dozena, luz, nariz \\
\hline & ç & $\begin{array}{l}\text { çapato, çoçobra, çumaque / } \\
\text { careçe, çierto }\end{array}$ & $\begin{array}{l}\text { pieça, esperança, cabeça, pe- } \\
\text { daço, moço, cierto, principio }\end{array}$ \\
\hline & $\mathrm{x}(\mathrm{exe})$ & $\begin{array}{l}\text { xabon, axedrez, exemplo, } \\
\text { coxo }\end{array}$ & $\begin{array}{l}\text { baxas, quexan, exemplo, } \\
\text { dixo, dixe, coxo, dexo }\end{array}$ \\
\hline \multirow[t]{2}{*}{ torinas } & $\mathrm{m}$ & encomendar / encommendar & emendarse \\
\hline & $\tilde{\mathrm{n}}$ & maña, montaña, campaña & hazañas, maña, señales \\
\hline 1 & 1 & \begin{tabular}{lll|} 
ilustre / illustre, Tulio / \\
Tullio
\end{tabular} & ilustre \\
\hline \multicolumn{4}{|l|}{ consonantes mudas } \\
\hline \multirow[t]{2}{*}{ del primer orden } & $\mathrm{f}$ & $\begin{array}{l}\text { efeto / effeto, aficion / affi- } \\
\text { cion, filosofia / philosophia }\end{array}$ & efeto, filosofia \\
\hline & v (ve) & $\begin{array}{l}\text { voluntad, variedad, advertir, } \\
\text { escrivir / uoluntad, uariedad }\end{array}$ & voluntad, diversas \\
\hline \multirow[t]{4}{*}{ del orden segundo } & c (cace) & $\begin{array}{l}\text { carta, como, culpa, merced, } \\
\text { excelso, facil, cinco }\end{array}$ & $\begin{array}{l}\text { cartas, como, cultura, merce- } \\
\text { des, facil, cinco }\end{array}$ \\
\hline & g (gage) & $\begin{array}{l}\text { manifico, mananimo / mag- } \\
\text { nifico, magnanimo, higado, } \\
\text { gordo, agudo, Geronimo, gil }\end{array}$ & $\begin{array}{l}\text { manifico, mananimo, inoran- } \\
\text { cia, dinos, agudo, ageno }\end{array}$ \\
\hline & j (ja) & alhaja, ojo, juan & ojos \\
\hline & ch (ache) & mucha, mucho, machuca & mucha, mucho \\
\hline del orden tercero & h (ha) & $\begin{array}{l}\text { Cristo, caridad, ortografia / } \\
\text { christo, charidad, orthografia }\end{array}$ & Caridad, Atenienses \\
\hline
\end{tabular}

Hemos podido comprobar que en la obra impresa de Furio escrita en "lengua Vulgar de España" se encuentran fielmente representadas todas las particularidades ortográficas exclusivas de la Gramatica, aplicadas con coherencia y de manera sistemática, y sabemos también que Furio era especialmente cuidadoso en la revisión de las pruebas de imprenta de su producción, como más arriba hemos señalado, por lo que no es extraño pensar que ese esmero en la revisión nazca 
de la preocupación del autor por una impresión respetuosa con sus particulares normas ortográficas. Si se da por válida la autoría de esta gramática por Furio, la defensa y puesta en práctica de su propia teoría ortográfica demostraría una vez más su talante inconformista e innovador, en esta ocasión frente a la desalentadora inercia de la ortografía tradicional.

\section{La Gramatica en relación con la obra manuscrita: informes oficiales y} correspondencia particular

Con respecto a la producción manuscrita de Furio, hay que partir de la importante premisa de que una parte considerable de la misma se conserva en copias que no han sido respetuosas con la praxis escrituraria de Furio.

La documentación manuscrita de Furio se clasifica en cartas, memoriales o informes, la Petición a Felipe II para obtener el cargo de vicecanciller de la Corona de Aragón ${ }^{24}$, y el codicilo autógrafo de 1589, su último documento conservado (Almenara, 1995) ${ }^{25}$. Hay que reconocer que los resultados del análisis de esta documentación no son tan concluyentes como los de su obra impresa, si bien hay que tener en cuenta que las características propias de este tipo de documentación podrían justificar las desviaciones de la teoría ortográfica de Furio, al darse una mayor relajación a la hora de redactar documentos privados, que no estarían sujetos a una meticulosa revisión ulterior por parte del autor.

Como ejemplo y resumen de estas conclusiones incluimos un breve fragmento de la Petición a Felipe $I^{26}$ :

[Fol. 1r $\mathrm{r}$ s/n] "Católica Real Magestad:"

Los grandes Filósofos, i Theólogos de commún consentimiento afirman, que entre la Ambición, i la Petición hai esta diferencia, que la Ambición, sin respecto del bien público, dessea, pide, i procura para sí mesma, para sus apetitos, i interesses, hora los meresca, hora no los meresca; i por esta causa aplica los favores, i los cohechos, trabajando por todas las vías de salir con sus pretenciones, sin querer someterse al juizio, ni a la determinación de la prudente, i justa censura de a quien le pertenesce hazerla: i si por caso no sale con su intento, queda corrida, furibunda, i desesperada.

Tanto en la Petición como en el Codicilo, los dos textos autógrafos, existe concordancia en la ortografía: $y$ no aparece nunca, distinción $u / v$, uso de $c$ únicamente ante $a$ y $o$, y nunca ante $e$, $i$. Respecto de las desviaciones de las normas de la Gramatica, aparece la grafía th en Theologos y Theologia, pero

24 Una parte de estos materiales son inéditos.

25 En la transcripción de este texto se deslizan algunos errores relativos a $y$ en vez de $i$.

26 IVDJ, Envío 93, doc. 164; Zabálburu, carpeta 219 - 19 (Furió); véase también Méchoulan (Furio Ceriol, 1993: 91-95), quien no obstante no ha podido consultar los originales. 
también Filosofos y Filosofia; grupos consonánticos como destruction y election, o la grafía sciencia. Como en el resto de la documentación manuscrita de Furio, la $i / y$, y la $c ̧$ son los rasgos ortográficos más constantes, la $u / v$ el menos $^{27}$. Este último aspecto no es extraño, ya que sistematizar la incorporación de esta novedosa distinción frente a una tradición estandarizada debía entrañar una notable dificultad incluso para el propio autor, que no debía de escribir con la misma concentración ni presión que cuando realizaba la tarea de revisar y corregir unas pruebas de imprenta.

\section{ARGUMENTOS DE ESTILO}

El estilo es otro de los rasgos que acercan la Gramatica a la obra impresa de Furio, El Concejo. Sobre todo destaca en ambas la rotunda asertividad de las afirmaciones y postulados, que se refuerza con numerosos paréntesis explicativos y con expresiones y fórmulas muy características. El estilo de ambas obras ofrece un uso muy frecuente de comas y frases parentéticas, y una organización altamente esquematizada ${ }^{28}$; en palabras de D. Sevilla (Furio Ceriol, 1952: 30), la forma de escribir de Ceriol se caracteriza por un estilo "cortado y seco, su rara ortografía y su sintaxis enrevesada".

Para esta ocasión hemos seleccionado las fórmulas de asertividad, de preterición y de conclusión:

27 En el caso de la Petición, por ejemplo, encontramos 25 casos de v: favores (2), provechosa, favorecida, provechos, vivir, diversas/diversos (2+2), aventajado/-os, provincias, evidentes, nuevo, aprovarlas, triviales, observancia, sobrevinieron, nueve, observar, Vniversidades, Avisos, provadas, conserve; frente a 4 de $u$, que podrían considerarse "errores": ciuiles (2), boluer, obseruación. Hemos examinado nueve escritos de Furio que consideramos autógrafos: 1. Al rey (AGS Consejo y juntas de hacienda 38 (moderno) / 96 (antiguo), 268 (Truman, 1979: 364), marzo de 1565); 2. Al príncipe de Mélito (AGS, Estado 563, 69, 26 de junio de 1575); 3. Al conde de Chinchón (Zabálburu, carpeta 219, 19, s/f., 14 (o 24)-10-1581); 4. Confutación para el cargo de vicecanciller de Aragón (Zabálburu, Carpeta 219, 19, 14-10-1581); 5. A Mateo Vázquez (Zabálburu, carpeta 219, 19, s/f., 16-12-1581); 6. A Mateo Vázquez (Zabálburu, carpeta 219, 19, s/f., 13-01-1582); 7. Capa i espada (Zabálburu, Carpeta 219, 19, -1582); 8. A Mateo Vázquez (IVDJ, Envío 96, 349, 04-06-1584); 9. A Mateo Vázquez (Zabálburu, 242, D.1/1, 18-06-1584).

28 Con relación a este aspecto, véase el apartado argumentos retóricos, pues esta organización altamente esquematizada responde al seguimiento a rajatabla de la dispositio oratoria que, junto con la colocación de las figuras es uno de los ejes sobre los que, como hemos indicado en otras ocasiones, Furio compone su ars rhetorica. 


\begin{tabular}{|l|l|}
\hline \multicolumn{2}{|c|}{ Fórmulas de asertividad } \\
\hline Gramatica & El Concejo, i Consejeros del Principe \\
\hline $\begin{array}{l}\text { Las letras de la lengua Vulgar se dividen en dos } \\
\text { partes, que io llamo esquadras (p. 10) } \\
\text { La v, que io la llamo ve (p. 25) }\end{array}$ & $\begin{array}{l}\text { si los Consejeros entendiesen esta parte de } \\
\text { la Republica, que io llamo cuerpo (f. 29v) } \\
\text { si es gobierno de uno solo, dicho Rei, que io } \\
\text { llamo Principe (f. 29v) }\end{array}$ \\
\hline $\begin{array}{l}\text { La c, que io le nombro cace (p. 26) } \\
\text { La g, que io nombro no g, sino Gage (p. 27) }\end{array}$ & $\begin{array}{l}\text { El segundo, es el de la paz [...] que io le } \\
\text { nombro Concejo de Paz (f. 5v) }\end{array}$ \\
\hline $\begin{array}{l}\text { Su nombre es ache, el qual se le ha puesto } \\
\text { mui impropiamente [...] por tanto io la la }\end{array}$ & $\begin{array}{l}\text { El primero, es de la hazienda; i assi le llamo } \\
\text { Concejo de hazienda (f. 4r) } \\
\text { llamo Ha (p. 29) }\end{array}$ \\
$\begin{array}{l}\text { El tercero, es de la guerra; i assi le llamo } \\
\text { Concejo de guerra (f. 6r) } \\
\text { El quarto, es de mantenimientos, o provisiones; i } \\
\text { assi le llamo Concejo de mantenimiento (f. 8v) } \\
\text { lo mas ordinario es nombrarla Rei, io la lla- } \\
\text { mo Principe (Prólogo Aii) }\end{array}$ \\
\hline
\end{tabular}

\begin{tabular}{|c|c|}
\hline \multicolumn{2}{|c|}{ Fórmulas de preterición y de conclusión } \\
\hline Gramatica & El Concejo, $i$ Consejeros del Principe \\
\hline $\begin{array}{l}\text { Por las quales causas, } i \text { otras que } \\
\text { adrede callo }(\mathrm{p} .8)\end{array}$ & $\begin{array}{l}\text { Dexo aparte i callo otros muchos vicios (Prólogo Aiiii) } \\
\text {.. pero parescióme a mí por justas causas que me } \\
\text { callo (por no ser prolixo) nombrarle Concejo (f. } 1 \mathrm{v} \text { ) } \\
\text { I allende desto se recrescen otros daños, los quales } \\
\text { callo por no ser prolixo (f. 14r) } \\
\text { Otros modos, que hai muchos de conoscer esta sufi- } \\
\text { ciencia por dichos i hechos, a sabiendas callo (f. 40r) } \\
\text { Dexo i callo a sabiendas otras muchas } i \text { mui bue- } \\
\text { nas razones, que a este proposito se podrïan traher } \\
\text { (f. } 76 \mathrm{r} \text { ) }\end{array}$ \\
\hline $\begin{array}{l}\text { i esto basta para lo que se deve saber } \\
\text { (p. 8) }\end{array}$ & $\begin{array}{l}\text { Baste que desto poco se entienda lo demas (f. 13v) } \\
\text { Basta en conclusión desto, que las Leies,... (f. } 24 \mathrm{r} \text { ) } \\
\text { para con este lugar basta saber que como... (f. 55v) } \\
\text { Baste saber, que dentre muchos buenos mas facil } \\
\text { es de escoger uno ecelentissimo que dentre pocos } \\
\text { (f. } 70 \mathrm{r} \text { ) } \\
\text { basta agora dezir, que con el, queda el Principe } \\
\text { mas descansado (f. } 77 \mathrm{v} \text { ) }\end{array}$ \\
\hline $\begin{array}{l}\text { I con esto se acaba lo que pretendïa } \\
\text { dezir acerca de los Diptongos (p. 16) } \\
\text { I con esto se acaba todo lo del Pro- } \\
\text { nombre de la primera persona (p. 38) } \\
\text { I aqui se acaba la declinacion de los } \\
\text { Pronombres (p. 44) } \\
\text { I con esto se acaba la primera de- } \\
\text { clinacion de los Verbos de la lengua } \\
\text { Vulgar (p. 48) }\end{array}$ & $\begin{array}{l}\text { Aqui se acaban las quinze calidades, por las qua- } \\
\text { les se suele conoscer la suficiencia del Consejero } \\
\text { en quanto al alma (f. 53v) }\end{array}$ \\
\hline $\begin{array}{l}\text { Con esto pongo fin a todo lo de las } \\
\text { Vocales (p. 16) } \\
\text { I con esto pongo fin a lo que toca a } \\
\text { las mudas (p. } 28 \text { ) } \\
\text { I con esto pongo fin al Pronombre de } \\
\text { la segunda persona (p. } 39 \text { ) }\end{array}$ & $\begin{array}{l}\text { I con esto pongo fin a las calidades i señales, que } \\
\text { mostran la suficiencia del Consejero en quanto al } \\
\text { cuerpo (f. } 62 \mathrm{v} \text { ) }\end{array}$ \\
\hline
\end{tabular}




\section{ARGUMENTOS RETÓRICOS: EL ORDEN}

El orden es fundamental en la retórica de Furio Ceriol. Lo considera la base de la organización del discurso, y sus textos responden a un esquema preestablecido del que no se desvía (Ferragut y Grau, 2016: 52-55), como se ha observado tanto para su Bononia (Wilke, 1996: 201-210; García Pinilla, 2003: 453-462) como para El Concejo (Ferragut y Grau, 2016: 57-62). Por ceñirnos únicamente a la estructura general de cualquier obra de cualquier género literario, Furio establece 6 partes del discurso: exordio, narración, proposición, partición, causa y peroración. Sin embargo, todo el orden gira, de hecho, en torno a la proposición y la partición, que constituyen el centro, el hardcore al que flanquean las partes previas (exordio y narración) y las sucesivas (causa y peroración). El orden propuesto en la partición debe ser siempre respetado y seguido, siendo, quizás, las más significativas, las siguientes afirmaciones de las Institutiones Rhetoricae:

Partitio [...] Rem enim diuisam certo ordine, ut facilius intelligimus, sic tenacius retinemus. Quamobrem peruelim ipse cum aliis omnibus scribendi generibus, tum in / [130] tradendis disciplinis hanc partiendi rationem religiosissime, ut ita dicam, coli, seruari. Ex hac enim uirtute una praeter caeteras manat praeclara illa laus, uia et ratione interpretandi (Institutiones, pp. 129-130).

[Partición (...) De esta manera tenemos el tema más sólidamente distribuido según un orden determinado para poder entenderlo con más facilidad. Por este motivo, quisiera ardientemente que este sistema de distribución sea cultivado y observado, tanto en las demás modalidades literarias, como / [130] en la enseñanza de las disciplinas, con total escrupulosidad. De esta virtud, pues, de la interpretación metodológica y racional, deriva, por encima de los demás, su principal beneficio].

Huius partis certissimum praeceptum est ut ad partitionem per omnia respondeat. Loquar apertius, uidendum est diligentissime, ut in causae tractatione, quo / [138] quidque ordine in partiendo positum fuerat, eodem disputetur, ita ut quod primum in partitione distributum erat quodque secundum, primo uel secundo loco tractetur (Institutiones, pp. 137-138).

[El precepto más importante de esta parte del discurso [causa] es que debe corresponderse con la partición punto por punto. Lo diré más claramente: debe procurarse con la mayor atención que en el tratamiento de la causa / [138] todo se discuta en el mismo orden en que se había dispuesto en la partición, de modo que lo que en la partición se había colocado en primer lugar, sea tratado en primer lugar, y lo que estaba en segundo lugar sea tratado en el segundo].

Del mismo modo, dentro de la causa, la parte más importante de cualquier 'discurso', en tanto que en ella se desarrolla la quaestio, es decir, el tema del que se trata, admite a su vez internamente tantas partes del discurso como sean necesarias en una especie de anillos concéntricos, o según la imagen que propone Furio, como afluentes de un río (Institutiones, pp. 136-137). 


\section{La partes del discurso de la Gramatica}

La Gramatica se inicia con una exposición, más narración que exordio a re, por el hecho de que se ocupa de un estado de la cuestión sobre las lenguas habladas en España, antes que de una aproximación 'emocional' al tema, al tratarse de una justificación, también, de la denominación de la lengua, y por lo tanto del título de la obra.

Parece ser, pues, que la Gramática carecería de exordio, es decir, de la presentación propiamente dicha, donde se suele aludir al autor o a los lectores o al tema $^{29}$, hecho bastante extraño. Sea como fuere, tras esta introducción se procede a la proposición:

Desta pues quiero dar al presente tales reglas i precetos, que todo hombre de qualquier nación que fuere pueda mui facilmente, i en breve tiempo hablarla, i escribirla mas que medianamente (Gramatica [Balbín y Roldán, 1966: 9]).

E inmediatamente establece la partición para conseguir tal fin: "en quatro maneras dichas Ortografia, Etimologia, Sintaxe i Prosodia". Deja las dos últimas al uso común, "de do se aprenderan mejor i mas facilmente". De este modo, solo se ocupará de las dos primeras, "porque dellas depende la conición necessaria desta lengua", que constituirán la división en dos libros, el primero sobre la ortografía y el segundo sobre la etimología, en los que se tratará no todo "quanto se pudiere dezir, sino lo que a mi me paresciere ser necessario para la instrucion de un principiante. Comienço por la primera parte". Es decir, no todo lo que se puede decir, sino lo que el autor considere necesario según su criterio.

El primer libro comprende desde la página 5 a la 30, y el segundo desde la 30 a la 64, y constituyen la causa de la Gramatica, es decir, la parte principal de la obra. La obra concluye con una breve peroración, aunque hay otra peroración también al final del primer libro tal y como apunta y practica el mismo Furio en las Institutiones Rhetoricae:

Enumeratio locum habet in omni causarum genere, sed praecipue in artium praeceptionibus, qua utendum censeo, cum alias quoties ad insignem aliquam operis partem fit transitus, tum praecipue uel necessario potius ad extremum opus (Institutiones, p. 147).

[La enumeración tiene cabida en todo tipo de causas, pero sobre todo en la enseñanza de las artes; pienso que debe utilizarse siempre que se hace el paso a alguna parte importante de la obra, y principal y necesariamente al final de la obra].

29 “A rebus igitur sumetur exordium, si demonstremus ea quae dicturi sumus uel magna, uel noua, uel inusitata, uel incredibilia, uel necessaria esse, uel intellectu digna” (Institutiones, p. 111). [El exordio se toma de las cosas, si mostramos que aquello que vamos a decir es grande o nuevo, inusual o increíble, necesario o digno de conocerse]. 
La primera peroración al final del primer libro no se señala con ningún rótulo, pero es introducida con las siguientes palabras (Gramatica [Balbín y Roldán, 1966: 29]): "He dicho brevemente quanto me parescio convenir a la Ortografía dela lengua Vulgar: agora en conclusión digo dos cosas", donde enumera claramente la ordenación de las letras según los criterios seguidos; y en la segunda parte de esta peroración, que debe ser de carácter emocional (incitar al amor o al odio, o bien lamentar), aconseja al que quiera aprender la lengua Vulgar que hay que observar el habla de los que utilizan la lengua "propia i elegantemente" y que la ortografía, la escritura, debe responder al habla.

En la peroración final de la Gramatica (Balbín y Roldán, 1966: 64), extraordinariamente breve, se recuerda cuál ha sido el orden seguido y que el autor se ha ajustado al mismo, procediendo a la enumeración y, acto seguido, la inflammatio amoris en que anima al estudio de la gramática a los que "quizieren aprender bien i presto esta lengua".

El hecho de que aparezca la peroración es una característica de las ediciones de Furio, tanto en las Institutiones como en El Concejo, organización que a su vez toma de las ediciones de los Institutionum Dialecticorum Libri III de Petrus Ramus. Así, la Gramatica sigue las partes del discurso propuestas por Furio en su Retórica: exordio/narración, proposición y partición, causa (el desarrollo de la gramática) y peroración y una forma de exposición basada en el orden muy acorde con la teoría y la práctica de Furio Ceriol.

\section{ARGUMENTOS IDEOLÓGICOS}

La ideología del autor de la Gramatica se deja ver, sobre todo, en el texto introductorio a la misma. Sus ideas pueden resumirse en las siguientes: 1. Conciencia de la diversidad lingüística de España ${ }^{30} ;$ y 2. Inexistencia de una jerarquía natural entre las lenguas por la que, de entrada, unas sean superiores o inferiores

30 Esta conciencia también se manifiesta claramente en la Vtil y breue institution para aprender los principios y fundamentos de la lengua hespañola, Lovaina 1555, (Roldán, 1977: 4): "Esta lengua dela que damos aquí preçeptos, se llama Hespañola: llámasse assí, non porque en toda Hespaña se hable una sola lengua, que sea universal a todos los habitantes della, porque ay otras muchas lenguas: sino, porque la mayor parte de Hespaña la habla". Gómez Asencio es quien con más detalle ha estudiado la teoría gramatical explícita y sobre todo implícita, tanto en la Vtil y breue de 1555 como en la Gramatica, identificando y exponiendo sus principales similitudes y estableciendo que "El desconocido gramático de 1559 tuvo atisbos originales e ideas no sostenidas por su antecesor [...] Pero nadie debe dudar de que conocía la obra de 1555 y la manejó con profusión; tampoco de que ocultó sagazmente y calló con prudencia su fuente" (Gómez Asencio, 1998: 865). Esta manera de proceder también la observamos en Furio Ceriol respecto de la principal fuente de sus Institutiones Rhetoricae. 
a $\operatorname{otras}^{31}$. El autor de la Gramatica hace gala de una conciencia muy clara de la diversidad lingüística de España, y es esa conciencia la que le lleva a cuestionarse cuál debe ser el nombre de la lengua objeto de su gramática, que unos llaman española y otros castellana. Esta doble denominación plantea al autor dos problemas: la primera designa el todo por la parte, puesto que en España existe más de una lengua; y la segunda, le plantea el problema de la parte por el todo, es decir, darle el nombre de una sola 'nación', cuando esta lengua no es exclusiva de la 'nación' castellana, en tanto que es compartida por Aragón y León, e incluso Portugal. Con todo, en el texto sí existe un criterio de valoración de las lenguas, al menos implícito, de acuerdo a tres principios: la antigüiedad, la cultivación literaria y su uso o extensión.

A continuación examinaremos con más detalle lo que dice acerca de cada una de ellas y analizaremos si estas ideas coinciden con las ideas linguiísticas de Fadrique Furio Ceriol $^{32}$.

\section{La lengua vasca}

La primera lengua que se menciona en la Gramatica es el vazquense, "que es la lengua de Viscaia, dela Provincia, i Navara (sic)" (Gramatica [Balbín y Roldán, 1966: 5]); se considera la más antigua de las que se hablan por toda España y procede del caldeo.

En primer lugar, el autor circunscribe el territorio de la lengua vasca, que incluye Vizcaya, la provincia, es decir, Guipúzcoa, y Navarra. Le atribuye la mayor antiguiedad entre las lenguas de la península, que es un criterio importante del prestigio de una lengua, y la hace derivar de la lengua caldea, es decir, la lengua semítica originaria de Mesopotamia identificada con el arameo antiguo y considerada una de las más antiguas entre las lenguas humanas, según afirma Furio Ceriol (1996: 326 y 1556: 76) por boca de Bononia. Respecto a la lengua vasca, Bononia la pone como ejemplo de una lengua pobre y malsonante equiparándola con el etíope y con cuya traducción la Biblia no ganaría nada en elegancia o belleza:

At ornatior et cultior erit, si in uulgares linguas uertatur. Num et ornatior et elegantior fuerit si Cantabrice aut Vasconice de Hebraeo aut Graeco aut Lati-

31 Lledó-Guillem (2011: 264-266) opone a esta visión jerárquica, que ejemplifica en la figura de Benito Arias Montano, una concepción más igualitaria de las lenguas, representada, precisamente, por el prólogo de la Gramatica y las ideas de Furio Ceriol, a los que empareja sin relacionarlos entre sí. En el primer caso apunta a la ya señalada conciencia de la diversidad lingüística de España y en el segundo a las ideas lingüísticas que aparecen en el Concejo i Consejeros del Príncipe, en tanto que el príncipe debe conocer y usar las lenguas de los pueblos sobre los que gobierna (cfr. Furio, 1996: 102 y 1559: 20r).

32 A propósito de la Gramatica, García Lenza (2007: 60) observa "cierto toque personal del anónimo autor (a veces polémico y combativo en sus observaciones) que la singulariza dentro de la tradición gramatical del español", características que encajan perfectamente con nuestro humanista. 
no interpretetur? num si in Aethopium linguam transferatur? Atqui his linguis nihil incultius, nihil inortatius, nihil horridius (Furio, 1996: 278 y 1556: 29). Pero será más culta y más literaria si se traduce a lenguas vulgares. ¿Sería más elegante y literaria si se tradujese al cántabro o vascuence a partir del hebreo, del griego o del latín? ¿O si se tradujera al etíope? Pero nada hay mas seco, más llano, más vulgar que estas lenguas (Furio, 1996: 279).

Sin embargo, Furio responde a estas palabras de Bononia con una emotiva afirmación de la igualdad de todas las lenguas, tanto en bellezas intrínsecas como en capacidades y potencialidades expresivas:

Omnibus linguis uulgaribus sua est copia, suus ornatus, sua elegantia, suus lepos ob eamque rem si fideliter nec sordidis uerbis Scriptura interpretetur, non poterit non culta et ornata apparere (Furio, 1996: 458 y 1556: 202-203). Todas las lenguas vulgares poseen su propia riqueza, su propio ornato, su propia elegancia y belleza; y por esta razón si la Escritura se interpreta fielmente y sin palabras soeces, necesariamente parecerá culta y adornada (Furio, 1996: 459).

Aunque en Bononia Furio Ceriol no se refiere en detalle al euskera, al menos sí lo menciona y lo considera, como a las demás, una lengua completa y perfectamente capaz para recibir en ella el contenido de las Sagradas Escrituras.

\section{La lengua arábiga}

La lengua Aráviga, procedente de la hebrea, ocupa el segundo lugar por su nobleza y antigüedad, y por las obras escritas en ella por "muchos Españoles". Se habla "en el reino de Granada, del'Andaluzïa, de Valencia, i Aragón”. Esta mención del árabe como lengua de España y la consideración de españoles a los que la utilizaron y la utilizan, ha llamado la atención de García Lenza (2007: 62), que considera que el autor de la Gramatica "revela una sana tolerancia hacia la diversidad cultural"33. De hecho, considera el árabe la segunda lengua de la península en importancia, por su antigüedad y por sus aportaciones al conocimiento y propiamente literarias. Furio Ceriol (1996: 548 y 1556: 289) menciona una sola vez en su Bononia la lengua árabe, justamente para ilustrar la traducibilidad inherente a las lenguas humanas y reconocer que de ella se tradujeron antaño y en la actualidad gran cantidad de obras tanto al latín como a otras lenguas vernáculas (uel in Latinum uel aliam linguam uernaculam). Sin embargo, es sobre todo en El Concejo, donde Furio expresa de manera meridianamente clara su falta de prejuicios religiosos o raciales:

33 También Rodrigo (2015: 76) considera que el autor de la Gramática hace gala de "insólita apertura" al considerar españoles a los que se expresan en lengua árabe. 
No hai mas de dos tierras en todo el mundo: tierra de buenos, i tierra de malos. Todos los buenos, agora sean Iudíos, moros, gentiles, Cristianos, o de otra secta, son de una mesma tierra, de una mesma casa i sangre: i todos los malos, dela misma manera (Furio, 1996: 112 y 1559: 41v).

Por decirlo en los términos de Méchoulan (Furio, 1996: 54-55 y 1993 XXVII), "no debemos olvidar que estas palabras fueron escritas en 1559, cuando España ponía todo su orgullo en la pureza de su raza y de su fe", y que "la menor huella de sangre judía o mora, cualquiera que fuese la distancia genealógica, bastaba para verse excluido de todo cargo o empleo de algún relieve y para ser tenido bajo constante vigilancia". Es bajo la consideración de estas ideas dominantes donde hay que apreciar lo chocante, si no desafiante, de la afirmación de Furio. Sus ideas, pues, son compatibles con la consideración de 'españoles' de los 'árabes', tanto como los demás y, por supuesto, la aceptación de su tradición literaria como un legado propio.

\section{La lengua catalana}

La lengua catalana, que merece un lugar aparte por su literatura, es una lengua 'verdaderamente' francesa procedente de Gascoña, y Limoges en concreto: "hablase en ella en los reinos de Cataluña, de Valencia, Mallorca, Menorca, Iviça, i aun en Nápoles”. Las lenguas provenzal y catalana son la misma a los ojos del autor, y se equipara con la árabe en cuanto a cultivación y producción literaria.

Furio Ceriol pone en boca de Bononia esta misma idea, al argumentar que la variedad dialectal es un obstáculo para la traducción de la Biblia a una lengua vulgar:

Vertatur, si uis, in Hispanicam linguam et quoniam cum Valentino suscepta est mihi disputatio, in uestratem linguam transferatur. Scis non minorem esse in uestrati lingua uarietatem quam in Italica. Clamabit igitur Cathalonia uniuersa male uersam esse quoniam multa, suo iudicio, inueniet inculta, barbara, impropria et a legitima Bibliorum sententia aliena plane. Idem dicet Balearis, idem Ebusius; est enim horum omnium regnorum communis uobiscum sermo et lingua, quanquam sono, prolatione et oris diductione nonnullis in locis differatis (Furio, 1996: 336 y 1556: 84).

Que se traduzca, si quieres, a una lengua hispánica, y puesto que yo he mantenido una polémica con un valenciano, que se vierta a vuestra lengua; sabes que en vuestra lengua no hay una diversidad menor que en la italiana. Gritará, así pues, Cataluña entera que ha sido mal traducida, porque, en su opinión, encontrará muchas cosas descuidadas, extranjeras, inadecuadas y completamente ajenas a los legítimos contenidos de la Biblia. Lo mismo dirán las Baleares, lo mismo Ibiza, pues el habla y lengua de todos estos reinos es común con vosotros aunque os diferenciéis en algunos puntos en el sonido, en la pronunciación y en la abertura de la boca (Furio, 1996: 337) 34. $^{34}$

\footnotetext{
${ }^{34}$ Hemos modificado ligeramente la traducción ofrecida en la edición de Bononia en el primer volumen de las Obras Completas de Furio Ceriol (Furio, 1996: 337). Evidentemente, Hispanicam
} 
La similitud con los términos con que se expresa el autor de la Gramatica nos parece evidente, sobre todo por la claridad con que alude a la unidad de la lengua catalana y la enumeración de los territorios en los que se habla, aunque sea para enfatizar sus diferencias, de índole básicamente fonética. A este argumento de Bononia responderá Furio (1996: 590-591 y 1556: 332) más adelante, pero solamente refiéndose a la variedad dialectal del italiano — no dice nada de su propia lengua-, quizás por cortesía con el italiano Bononia (Colón, 1980: 128), arguyendo que las diferencias linguiísticas entre un toscano (Hetruscus), un ápulo (Apulus, de la Puglia) o un lombardo (Ligubardus), son más de 'estilo' o de 'elegancia' y que no hay problemas de intercomprensión. En todo caso, defiende que se puedan renovar las traducciones cada cierto tiempo, y si es necesario traducirse a los dialectos y lenguas correspondientes. Así, concluye Furio (1996: 592 y 1556: 333) que el ejemplo utilizado respecto a la variedad del italiano (Italicae linguae de uarietate) sirve también de [uarietate] Gallicae et Hispanicae et Germanicae, caeterarumque nationum.

Por su parte Rodrigo (2015: 77) achaca confusión y "desconocimiento idiomático" al autor de la Gramatica por citar como mérito de la lengua catalana los versos de la Commedia de Dante en que su maestro Arnaut Daniel se expresa en provenzal $^{35}$. Pero no es desconocimiento, sino que el autor considera el provenzal la misma lengua que el catalán, como considera el portugués la misma lengua que el castellano. No se trata de un error, sino de la creencia general, basada en la tradición literaria, que se tenía sobre el origen del catalán ${ }^{36}$, lo que hace más que probable que el autor de la Gramatica fuera catalanohablante.

\section{Ni español ni castellano: Vulgar}

En último lugar, el autor llega al objeto de su gramática. "El quarto lenguaje, es aquel, que io nuevamente llamo Lengua Vulgar de España, porque se habla, i

linguam puede traducirse como "lengua española", pero como el pasaje muestra cierta ambigüedad y no parece diferenciarse u oponerse drásticamente a la lengua hablada en Valencia a la que alude a continuación, hemos preferido ofrecer esta versión. Más adelante trataremos la cuestión del nombre de la lengua en la Gramatica y volveremos a aludir a este pasaje.

35 “Tan m'abellis vostre cortes deman, /qu'ieu no me puesc ni voill a vos cobrire. / Ieu sui Arnaut, que plor e vau cantan; / consiros vei la passada folor, / e vei jausen lo joi qu'esper, denan. / Ara vos prec, per aquella valor / que vos guida al som de l'escalina, /sovenha vos a temps de ma dolor!" (Purgatorio XXVI, vv. 140-147). En la Gramatica (Balbín y Roldan, 1966: 6) se atribuyen estos versos al "veinteno Canto" en vez de al XXVI, al que pertenecen.

36 Sobre este aspecto es destacable el estudio de Lledó-Guillem (2008: 61-62), quien indaga sobre la aparición de la denominación de valenciano para nombrar la lengua catalana hablada en el reino de Valencia, que empieza a aparecer a finales del siglo XV, tras la guerra civil catalana (14621472). En efecto, la denominación de valenciano o llengua valenciana no implicaba que se considerara una lengua diferente, aunque en la conciencia lingüística de los catalanohablantes se perfilaba una conciencia de discontinuidad entre la lengua medieval y literaria (el provenzal) y la actual, así como la afirmación de la personalidad jurídica de los valencianos ante una Cataluña en decadencia. 
entiende en toda ella generalmente, $i$ en particular tiene su asiento en los reinos de Aragón, Murcia, Andaluzïa, Castilla la nueva, i vieja, Leon i Portugal”. La primera singularidad, aparte de la denominación, es que considera el portugués y el castellano una misma lengua, aunque concede que "tiene tantas, i tales variedades en algunas palabras, i pronunciaciones, que bien se puede llamar lengua de por si", sin embargo, "toda vïa no es apartada realmente de aquella que io llamo vulgar, antes son una mesma cosa" ${ }^{37}$. No es pues la naturaleza de la lengua, sino el nombre lo que provoca una gran prevención. Rechaza el autor la denominación de española pues esta no es la única lengua de España, ni la más antigua, ni la más cultivada literariamente, y por lo tanto, no merecería la denominación del conjunto. Ya hemos visto que solamente Furio Ceriol en El Concejo denomina a esta como "Lengua Vulgar de España", como nombre propio de la lengua y no con el adjetivo 'vulgar'; sin embargo vamos a ver cómo se refiere a ella en Bononia.

En esta obra aparece la expresión Hispanica lingua en el pasaje ya citado a propósito de la lengua catalana y también en la respuesta, también citada, que ofrece más adelante en la obra. Hemos indicado que no parece mostrarse una oposición entre Hispanicam y uestratem linguam, sinó más bien la elección, como deferencia con el origen del adversario dialéctico, de su lengua, también Hispanica. Cuando más adelante Furio responde que la variedad dialectal no es un obstáculo para la traducción de la Biblia, ejemplificando con el italiano, se muestra consciente, asimismo, de la variedad linguiística/dialectal del 'galo', del 'hispánico' y del 'germánico'. Nada nos impide interpretar que Furio se esté refiriendo únicamente a las variedades del castellano o del francés, aunque no podemos excluir que piense también en las diferentes lenguas, más o menos próximas, habladas en tales territorios; pero lo que sí sabemos con certeza es que Furio tiene conciencia de la variedad de 'naciones' y lenguas existente en España cuando afirma que todas ellas tenían a su disposición la traducción de la Biblia a su lengua, aunque habían sido prohibidas por la Inquisición con el argumento de que los judíos conversos tomaban de ella sus ritos y ceremonias, y aunque en principio estas traducciones estaban permitidas a los no judíos, la prohibición acabó extendiéndose de forma general:

Idem in uniuersa Hispania cautum est, habebant enim fere reliquiae Hispaniae nationes etiam Biblia, in suam quaeque linguam uersam (Furio, 1996: $368 \mathrm{y}$ 1556: 112).

Lo mismo fue prohibido en toda España, pues casi todas las demás nacionalidades de España tenían también la Biblia traducida a su lengua (Furio, 1996: 369).

37 La posible explicación para esta consideración del autor es que en la tradición literaria, castellano y galaico-portugués han ido de la mano, considerándose variantes 'estilísticas' o de género, de manera análoga a la relación entre provenzal y catalán en la tradición literaria catalana; de este modo, el autor, por analogía con esta, establece la unidad castellano-portugués basándose en la tradición literaria conjunta de ambas lenguas. Cfr. García Lenza (2007: 64-65). 
El término Hispania, al menos para Furio Ceriol, no designa todavía un Estado, sino un lugar geográfico en el que hay varios pueblos y varias lenguas ${ }^{38}$. Y de manera más clara todavía para el autor de la Gramatica, quien no se refiere con el término España ni siquiera a los territorios 'hispánicos' bajo un mismo soberano, pues en el momento en que se publica, 1559, Portugal todavía no forma parte de los dominios de Felipe II, hecho que tanto García Lenza (2007: 64-65) como Rodrigo (2015: 79) han subrayado, sino a lo que hoy en día conocemos como península ibérica.

Lo más sorprendente, de todos modos, es el rechazo de la denominación de lengua castellana o castellano, "aunque no paresce desaforado", por ser un nombre demasiado "ambicioso i lleno de imbidia", toda vez que los reinos de León y Aragón "tiene maior i mejor derecho en la lengua Vulgar, que no el reino de Castilla”. Esta refutación es bastante más problemática y se fundamenta en una idea de la lengua basada más en la historia política que en la propiamente linguiística: León y Aragón tienen más derecho sobre la lengua que Castilla, pues son reinos anteriores al de Castilla, y las tierras de la Castilla originaria, o bien han estado supeditadas a León, o bien a Aragón. El autor, como ha sido señalado ya por García Lenza (2007: 65 y 67), no menciona las lenguas leonesa ni aragonesa y los argumentos que da en contra "no tienen mucho sentido". Sin embargo, si examinamos la lógica de este autor, para quien el castellano y el portugués son "toda vïa" la misma lengua, seguramente consideraría como meras variantes tanto el astur-leonés como las diferentes modalidades de aragonés ${ }^{39}$. Furio Ceriol, por su parte, utiliza una sola vez esta denominación para referirse a la lengua castellana:

Vidi etiam ac legi epistolas Pauli carmine interpretatas, tum mea, tum Castellanica, ut uocant, lingua (Furio, 1996: 588 y 1556: 329).

Yo mismo he visto y leído las epístolas de san Pablo traducidas en verso, tanto en mi lengua, como en la que llaman castellana (Furio, 1996: 589).

Obsérvese la prevención introducida por Furio para referirse a tal denominación: ut uocant. Es cierto que no necesariamente esta matización ha de entenderse como un punto de desacuerdo con esa denominación, ya que Bononia se publicó en Basilea y no iba dirigido, obviamente, a un público exclusivamente español,

38 Un ejemplo de ello lo tenemos en el hecho de que Felipe II no se convertirá formalmente en rey de los diferentes reinos de la Corona de Aragón sino tras celebrar cortes en Monzón y tras jurar las constituciones de cada uno de ellos entre 1563 y 1564 (Fernández Terricabras, 2018: 68, §3); y que, por ejemplo, la famosa Pragmática de 1559 prohibiendo a los estudiantes 'españoles' estudiar en universidades extranjeras, solamente afecta a los súbditos de la Corona de Castilla, y no será hasta el 25 de mayo de 1568 cuando se registrará en la Corona de Aragón (Fernández Terricabras, 2018: 66, §47).

39 López García (1985: 78-80) remarca el carácter koinético de esta gramática, de acuerdo a su consideración de la lengua castellana como una koiné creada para la intercomprensión de hablantes de lengua vasca y de otras variedades románicas. 
de modo que simplemente puede introducir una manera de nombrar la lengua que no era la habitual, ni era la más conocida fuera de la península, donde ya se identificaba el español con el castellano, además de oponerse, en el mismo texto, al valenciano, otra lengua 'española'; sin embargo, en el contexto en el que se halla, donde Furio responde a Bononia, quien ha demostrado un buen conocimiento — quizás ficticio - de la pluralidad linguística de España, y en concreto de las variedades de la lengua catalana y de la base fonética de sus diferencias dialectales, esta prevención bien puede tener una connotación de un cierto prejuicio hacia tal denominación, coincidente con la del autor de la Gramatica.

Este rechazo de ambas denominaciones, castellano y español, por parte del autor de la Gramatica deja patente para Amado Alonso (1958: 51) no tanto, según entendemos, la "visible inquina [hacia Castilla] que le nubla el entendimiento", sino más bien la "tensión interior de España entre la nueva [español] y la vieja denominación [castellano]" (Alonso 1958: 48), lo que le lleva a concluir que "evidentemente, el autor no era castellano y, casi seguro, era del reino de Aragón" (Alonso 1958: 50). Amado Alonso se aproximó. El autor no era de Aragón, pero sí de su Corona, en concreto, del reino de Valencia.

En definiva, el autor de la Gramatica defiende el término Vulgar, por ser "la mas vulgar, la mas usada, i la que mas tierra ocupa en toda España". En palabras de García Lenza (2007: 66) "el común denominador linguístico de la comunidad hispánica”, en tanto que koiné española. Así, lengua Vulgar de España debe entenderse como la lengua más común entre todas las que se usan en la península ibérica $^{40}$.

\section{LOS POEMAS DEDICATORIOS DE LAS OBRAS DE FURIO Y EL DE LA GRAMATICA}

Las tres obras impresas de Furio tienen una característica formal común: después de la portada, aparece un único poema dedicatorio del autor, característica también presente en la Gramatica; las analogías, no obstante, van mucho más allá.

En las Institutiones Rhetoricae tenemos una composición en dísticos elegiacos en el que el autor se dirige a su libro y el título del poema es Fridericus Furius Caeriolanus ad librum suum. En Bononia es el libro el que habla y se dirige al dedicatario de la obra, el cardenal Francisco de Mendoza, en estrofas sáficas, y su título reza Liber alloquitur Franciscum Cardinalem. En El Concejo es también el libro el que se dirige al lector, aunque le cuenta las palabras que le dijo su padre, es decir, su autor, al despedirlo, combinando el soneto y la silva en una

40 Alonso (1958: 52-53) reflexiona sobre el término 'vulgar', que evidentemente se aplicaba a cualquier lengua 'natural' hablada, por oposición al latín fundamentalmente, pero no puede ver que 'España' o 'español', tanto en el autor de la Gramatica como en Furio Ceriol, no designa una entidad política concreta, sino que más bien es una simple denominación geográfica. 
composición de 14 más 12 versos, con un escueto título: El Libro. En último lugar, en la Gramatica, con un no menos escueto título (El Autor) también es el autor quien se dirige al libro, en una silva de 10 versos. Aunque este tipo de composición en la que el autor se dirige al libro o el libro habla por sí mismo no es desconocida en la poesia neolatina, resulta cuando menos curioso que las tres composiciones de Furio respondan a este artificio ${ }^{41}$. Si comparamos las composiciones de Bononia y El Concejo, en ellas el libro habla por sí mismo; en el primer caso el libro pide ayuda a su protector, el cardenal Mendoza, a quien llama pater, no solo ante las amenazas, sino ante los castigos que recibe. Así, en primer lugar alude a la presencia amenazante de los enemigos (toruos hostium uultus), y a su espalda desgarrada por la espada ensangrentada. En la segunda estrofa, menciona a los judíos que tratan de perderle con sus malas artes ${ }^{42}$. En la última estrofa, tras lamentarse de su persecución y acoso, pide ayuda al cardenal:

Liber alloquitur Franciscum Cardinalem. / Magne Mendozi, Referamne toruos / Hostium uultus, mihi qui cruento / Ense tergus dilacerant maligne et / Viscera nudant? / Eloquar: Scribae, Pharisaei, Iudas / Caiphas, Pilatus et omnis orbis / Iudaeorum perdere me laborant / Arte dolosa. / Hei mihi; eheu quam premor urgeorque, / Innocens! Succurre, Pater, mihique / Fer, rogo te, suppetias opemque / Ocius aura (Furio, 1996: 250 y 1556: 2).

Parlamento del libro al cardenal Francisco. Gran Mendoza, ¿te he de describir los torvos semblantes de los enemigos, que con la sanguinaria espada me despedazan las espaldas con malicia y dejan al descubierto las entrañas? Me explicaré: escribas, fariseos, Judas, Caifás, Pilatos y todo el mundo de los judíos trabajan para perderme con mañas capciosas. ¡Ay de mí! ¡Oh cuán oprimido y acosado estoy, aunque inocente! Padre, socórreme y acude, te lo ruego, en mi ayuda y auxilio mas rápidamente que el viento (Furio, 1996: 251).

Este mismo es el leitmotiv del poema de El Concejo. En primer lugar, el propio libro afirma que su autor es más libre que el propio albedrío, una clara manifestación de orgullo e insobornable independencia. Entonces oímos el consejo del autor: de estas armas, que consituyen el contenido de la virtud, debe proveerse si quiere defenderse de los golpes que la ignorancia y la malicia intentarán asestarle. Es pues, igual que Bononia, un libro perseguido por sus enemigos, que intentarán golpearle, pero la virtud vale mucho más que cualquier otra defensa. En definitiva, le anima a resistir, pues la resistencia le llevará a la victoria:

41 Esta forma de composición no es en absoluto predominante, si nos atenemos al Repertorio de J. F. Alcina (1995).

42 No debemos considerar por estos versos, aunque puedan inducirnos a pensarlo, que Furio Ceriol era antisemita, pues se muestra claramente contrario a una discriminación por razón de raza o religión en El Concejo (Furio 1996: 112 y 1559: 41v); más bien se trata de una mención de los responsables de la persecución de Jesús de Nazaret, alusión al engaño con que se puede perseguir el libro. 
El Libro: / Mi padre es un hombre que professa / tener más libertad que el alvedrio; / i al despedirme dixo: hijo mío, / de mis armas i arnés te me aderessa. / Malicia i inorancia se dan priessa / por su vano interesse que por frío / se tenga el sol; por donde el desvarío / nos manda el mundo todo, i nos lo opressa. / Por tanto diez mil golpes de contino / en ti descargarán fuera mesura, / por sacarte del mundo, los malditos. / Fieros golpes serán; mas ten buen tino, / que siendo de virtud tu armadura, / en menos los temas que de mosquitos. / Trabajos infinitos / han de passar por ti; mas ten memoria / que donde no hai trabajo, allí no hai gloria. / El mundo hace historia, / i muerto el interesse, vemos que uno / vale por mil, i mil mui menos que uno. / Iuzgarte han importuno, / o nescio, o loco, o bovo. Nada empesce; / que el hierro acicalado resplandesce. / El vulgo envilesce. / Mi padre aquí acabó de hablar conmigo: / también acabo io; lo mesmo os digo (Furio, 1996: 83-84 y 1559: s. p. [2]).

Bononia fue un libro polémico por el que su autor fue encarcelado y perseguido realmente; El Concejo salió a la luz en el año en que Furio fue perseguido y encarcelado de nuevo ${ }^{43}$. La misma idea de persecución se ve reflejada en ambos poemas.

Si comparamos el poema que encabeza las Institutiones y la Gramatica debemos considerar que ambas obras son artes: una retórica y una gramática. Así en el primer caso, Furio despide al libro, le dice: uade liber — — ve, libro—. Y le da los argumentos que debe responder a los que consideren que se trata de un "género" indigesto: no está hecho para gente dormida ni para gente de vientre "hinchado" —distenti abdomine uentres_; nada tiene que ver con ese tipo de lectores:

Fridericus Furius Caeriolanus ad librum suum. / Audi, quaeso liber, tibi sum dicturus in aurem / Paucula: siste gradum, uerbaque mente nota. / Dixi. Vade liber. Rides? Si forte molestum / Hoc genus esse uolet, talia dicta dabis. / O somnus Latmi! O distenti abdomine uentres! / Nil mihi uobiscum est, quaerite

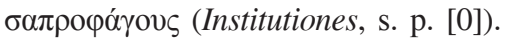

[Fadrique Furio Ceriol a su libro: Óyeme, te lo ruego, libro mío, te voy a decir al oído unas pocas palabras: detén el paso y toma nota de ellas. He dicho. Ve libre: ¿Ríes? Si acaso este género quiere ser pesado, darás tal respuesta: ¡Oh sueño de Latmo, oh vientres de flojo abdomen! No tengo nada que ver con vosotros: buscad a los saprófagos].

También despide el autor de la Gramatica a su libro en el primer verso: "sal de casa" y tampoco considera que su libro tenga algo que ver con "hombre torpe, o gruesso"; grueso de mente, de inteligencia, se entiende, aunque el mismo Furio nos da el significado en las Institutiones (1554: 262): “también gurdos, que el populacho latino empleaba en vez de stolidos, fue llevado por los hispanos a

43 Gielis (2018: 111-125) ofrece nuevos e interesantes detalles sobre los procesos a los que estuvo sometido Furio en Lovaina en 1556 y en 1559-1560 a partir de documentación conservada en los archivos de la Universidad de Lovaina no tenidos en cuenta hasta ahora. 
Roma", valiéndose del testimono del rétor de Calahorra, Quintiliano (inst. 1, 5, 57). Son evidentes las analogías entre ambos poemas:

El Autor. / Sus presto; sal de casa / osadamente libro; que es despecho / verte tan decaïdo, que te assombres / de ir entre los hombres, / con quienes has de hablar por su provecho. / Tu tienes sano el pecho, / i mui modesta lengua. / $\mathrm{O}$ que un malzin no cura nada desso! / Ni tu dél: porque es mengua / tenér cuenta con hombre torpe, ó gruesso (Gramatica [Balbín y Roldán, 1966: 4]).

En ambos, el autor alude al hecho de que el libro debe responder a sus "no lectores-detractores": talia dicta dabis / "has de hablar por su provecho", comentándoles que nada tiene que ver con las personas que no se ocupan ni se preocupan de su formación e intelecto.

\section{ÚLTIMAS CONSIDERACIONES}

¿Por qué motivos quedó anónima la Gramatica de la Lengua Vulgar de España, mientras que El Concejo, $i$ Consejeros del Principe aparece con el nombre de Furio?

En 1559 Furio fue de nuevo encarcelado en la Universidad de Lovaina por una acusación, probablemente de herejía, en algún momento de principios del mes de julio y fue liberado unos dos meses después, en torno al 10 de septiembre. Poco después, fue de nuevo encarcelado, y entre la sentencia del caso, el 7 de abril de 1560, y su huida de Lovaina el 26 de mayo del mismo, parece que permanecía todavía preso (Gielis, 2018: 120, 122-124) ${ }^{44}$. Anteriormente, en 1556, había estado también encarcelado, muy probablemente, a causa de la publicación de Bononia. Una obra como El Concejo, con su particular ortografía, y con el esmero de su corrección - recordemos que no hay una sola y en todo el tratadito-, ya debía de haber visto la luz corregida por su autor. La obra, editada en Amberes por la viuda de Nucio, no presentaba, en principio, ningún peligro para la imprenta, ni por su contenido, ni por su autor, en una ciudad comercial y con un ambiente mucho más relajado que el de Lovaina. Sin embargo, Gravio era el impresor de la Universidad, y uno de sus estudiantes, Furio, estaba siendo encausado por herejía. Quizás Gravio, asustado, decidió por su cuenta eliminar el nombre del autor y cualquier elemento, como una dedicatoria o presentación personal, que

\footnotetext{
44 Del trabajo de Gielis (2018: 120-124) parece deducirse que Furio permanecería preso desde finales de octubre de 1559 hasta su huida en mayo de 1560. Sin embargo, el mismo Furio afirma en una carta de octubre o noviembre de 1564, ya en España, dirigida a una personalidad eclesiástica, tal vez Fresneda, que "en días passados por mandado de Su Majestad fuy tristemente aprisionado con cadenas, con grillos, con esposas a las manos, con guardia en Lovayna, y en esta ciudad por más de dos meses y medio" (BNE MSS/20427/3).
} 
permitiera identificarlo, privando a la Gramatica del elemento introductorio que echamos en falta. La obra no tiene las características de un anónimo. Su autor escribe en primera persona, antecediendo pleonásticamente los verbos en primera persona con el pronombre Io en 21 ocasiones. "El autor" se dirige a su libro, y la edición está extrañamente falta de un exordio, es decir, de una presentación en forma de dedicatoria, de epístola al lector, o de ambas. Y teniendo en cuenta la personalidad de Furio Ceriol, no es probable que él pensara en dejarla anónima, sino más bien en fundamentar su praxis ortográfica en castellano mediante una gramática que la validara. Sin embargo, ¿por qué una vez vuelto a España nunca reivindicaría la autoría de esta obra? En su descargo hay que decir que Furio Ceriol jamás menciona en los manuscritos que se conservan, algunos que incluyen gran número de datos biográficos, las obras publicadas con anterioridad, ni Rhetorica, ni Bononia, ni El Concejo, aunque sí alude en varias ocasiones a su formación en derecho, filosofía y teología, a su experiencia política, a su conocimiento de lenguas, de historia y a sus varias dotes y competencias. Furio Ceriol fue un hombre singular, con unas ideas propias que no tenía reparo en manifestar con claridad, a pesar de resultar chocantes y en contra de opiniones dominantes y, como creemos haber demostrado con suficientes argumentos, Furio Ceriol también es el candidato más firme a la autoría de una gramática que valida su práctica ortográfica, también singular y única.

\section{BIBLIOGRAFÍA}

Acero Durántez, Isabel (2008): “Lexicografía plurilingüe de los siglos XVI y XVII", Philologia hispalensis, 22/1, pp. 7-36, <https://doi.org/10.12795/ph.2008.v22.i01.01>.

Alcina, Juan Francisco (1995): Repertorio de la poesía latina del Renacimiento en España, Salamanca, Universidad de Salamanca.

Almenara Sebastiá, Miguel (1995): "Documentación testamentaria del humanista valenciano Fadrique Furió Ceriol (1527-1592): Edición y comentario", Estudis: Revista de historia moderna, 21, pp. 89-112.

Alonso, Amado (1949): "Examen de las noticias de Nebrija sobre antigua pronunciación española", Nueva Revista de Filología Hispánica, 3/1, pp. 1-82, <https://doi.org/10.24201/nrfh.v3i1.142>.

Alonso, Amado (1958): Castellano, español, idioma nacional. Historia espiritual de tres nombres, $3^{\mathrm{a}}$ ed., Buenos Aires, Losada.

Andrés Escapa, Pablo, Elena Delgado Pascual, Arantxa Domingo Malvadi y José Luis Rodríguez Montederramo (2000): "El original de imprenta", en Francisco Rico, Pablo Andrés y Sonia Garza (eds.), Imprenta y crítica textual en el Siglo de Oro, Valladolid, Universidad de Valladolid, pp. 29-64.

Balbín, Rafael de y Antonio Roldán (eds.) (1966): Gramática de la lengua vulgar de España: Lovaina 1559, edición facsimilar y estudio de ..., Madrid, Consejo Superior de Investigaciones Científicas.

Casas Rigall, Juan (2010): Humanismo, gramática y poesía: Juan de Mena y los auctores en el canon de Nebrija, Santiago de Compostela, Universidade de Santiago de Compostela.

Colón, Germà (1980): "L’humanista Furió Ceriol i la unitat de la llengua”, en Estudis de llengua i literatura catalanes I. Homenatge a Josep. M. de Casacuberta, Badalona, Abadia de Montserrat, pp. 117-130. 
Cordero, Martín (1556): "La manera de escrevir en castellano, o para corregir los errores generales en que todos casi yerran", en Las quexas y llanto de Pompeyo adonde brevemente se muestra la destrucion de la Republica Romana. Y el hecho horrible y nunca oido de la muerte d'el hijo d'el gran Turco Solimano dada por su mismo padre, con vna declamacion de la muerte por consolacion de vn amigo..., Anvers, En casa de Martin Nucio à la enseña de las dos Cigueñas, ff. 107r-127r.

Echenique, María Teresa y María José Martínez Alcalde (2013): Diacronía y gramática histórica de la lengua española, $2^{\mathrm{a}}$ ed., Valencia, Tirant Humanidades.

Esteve Serrano, Abraham (1982): Estudios de teoría ortográfica del español, Murcia, Universidad de Murcia.

Fernández Terricabras, Ignasi (2018): "De la crisis al viraje: Los inicios de la política confesional de Felipe II", en Michel Boeglin, Ignasi Fernández Terricabras y David Kahn (eds.), Reforma y disidencia religiosa: La recepción de las doctrinas reformadas en la península ibérica en el siglo XVI, Madrid, Casa de Velázquez, pp. 53-73.

Ferragut Domínguez, Concepción y Ferran Grau Codina (2016): "La praxis de la retórica en la obra de Fadrique Furio Ceriol", en Lillian von der Walde Moheno (ed.), Retórica aplicada a la literatura medieval y de los siglos XVI y XVII, México, Grupo Destiempos, pp. 39-95.

Furio Ceriol, Fadrique (1554): Institutionum Rhetoricarum libri III, Lovanii, Ex officina Stephani Gualtheri et Ioannis Bathenii.

Furio Ceriol, Fadrique (1556): Bononia, siue de Libris sacris in uernaculam linguam conuertendis, libri duo, Basileae, per Ioannem Oporinum.

Furio Ceriol, Fadrique (1559): El Concejo, i Consejeros del Principe. Obra de F. Furio Ceriol: que es el libro primero del quinto Tratado de la institucion del Principe, Anvers, En casa de la biuda de Martin Nucio.

Furio Ceriol, Fadrique (1952): El concejo y consejeros del príncipe y otras obras, edición, introducción y notas por Diego Sevilla Andrés, Valencia, Institución Alfonso el Magnánimo.

Furio Ceriol, Fadrique (1993): El concejo y consejeros del príncipe, estudio preliminar y notas de Henry Méchoulan, Madrid, Tecnos.

Furio Ceriol, Fadrique (1996): Obra completa I. El consejo y consejeros del príncipe. Bononia, Henry Méchoulan y Jordi Pérez Durà (codirs.), València, Edicions Alfons el Magnànim.

Galindo Romeo, Pascual y Luis Ortiz Muñoz (eds.) (1946): Antonio de Nebrija, Gramática castellana, Madrid, Edición de la Junta del Centenario.

García, Constantino (1971): Gramática castellana. Por el Licenciado Villalón, edición facsimilar y estudio de..., Madrid, Consejo Superior de Investigaciones Científicas.

García Lenza, Ana (2007): "Comentario de un texto hispánico del siglo XVI con temática lingüística: el prólogo de la Gramática de la lengua vulgar de España (Lovaina, 1559)", en Cristina Pérez Cordón y José Luis Ramírez Luengo (eds.), El español en sus textos: manual de comentarios lingüísticos e historiográficos, Lugo, Axac, pp. 59-70.

García Pinilla, Francisco Javier (2003): "La estructura de Bononia de Fadrique Furió Ceriol", en Ferran Grau Codina, Xavier Gómez Font, Jordi Pérez Durà y José María Estellés González (eds.), La Universitat de València i l'humanisme: Studia Humanitatis $i$ renovació cultural a Europa i al nou món, València, Universitat de València, pp. 453-462.

Gielis, Gert (2018): "«Cosas perniciosas y de mala doctrina»: El fallido proceso por herejía contra Fadrique Furió Ceriol en la universidad de Lovaina (1556-1560)”, en Michel Boeglin, Ignasi Fernández Terricabras y David Kahn (eds.), Reforma y disidencia religiosa: La recepción de las doctrinas reformadas en la península ibérica en el siglo XVI, Madrid, Casa de Velázquez, pp. 111-125.

Gómez Asencio, José Jesús (1998): "Los anónimos de Lovaina del siglo XVI juntos y en contraste", en Nicole Delbecque y Christian De Paepe, (eds.), Estudios en honor del profesor Josse De Kock, Leuven, Leuven University Press, pp. 855-869.

Kukenheim, Louis (1974): Contributions à l'histoire de la grammaire italienne, espagnole et française à l'époque de la Renaissance, Utrecht, $\mathrm{H}$ \& S. 
Lagomarsino, David (1978): "Furió Ceriol y sus «Avisos acerca de los Estados Bajos»", Bulletin hispanique, 80/1, pp. 88-107, <https://doi.org/10.3406/hispa.1978.4246>.

Lagomarsino, David (1979): "Furió Ceriol y la «Pragmática de las Cortesías» en 1586", Estudis: Revista de historia moderna, 8, pp. 87-104.

Lledó-Guillem, Vicente (2008): Literatura o imperio: la construcción de las lenguas castellana y catalana en la España renacentista, Newark, Juan de la Cuesta.

Lledó-Guillem, Vicente (2011): "Revisiting Early Modern Spain: The "Manifiesto por una lengua común' of 2008 and its Ideological Precedents", eHumanista, 17, pp. 254-270.

López García, Ángel (1985): El rumor de los desarraigados: conflicto de lenguas en la Península Ibérica, Barcelona, Anagrama.

Maquieira, Marina (2006): "Teoría y práctica ortográficas en las gramáticas del español del siglo XVI", en José J. Gómez Asencio (dir.), El castellano y su codificación gramatical I. De 1492 (A. de Nebrija) a 1611 (John Sanford), Burgos, Instituto de la lengua castellano y leonés, pp. 365-395.

Martos, Josep Lluís (2015): "Juan Martín Cordero en Flandes: Humanismo, mecenazgo e imprenta", Revista de Filología Española, 95/1, pp. 75-96, <https://doi.org/10.3989/rfe.2015.04>.

Moll, Jaime (2000): “Amberes y el mundo hispánico del libro", en Werner Thomas y Robert A. Verdonk (eds.), Encuentros en Flandes. Relaciones e intercambios hispano flamencos a inicios de la Edad Moderna, Leuven, Universitaire Pers Leuven, Soria, Fundación Duquesa de Soria, 2000, pp. 117-131.

Nebrija, Antonio de (2011): Gramática sobre la lengua castellana, edición, estudio y notas de Carmen Lozano, en Paginae Nebrissenses, al cuidado de Felipe González Vega, Barcelona, Galaxia Gutemberg, Círculo de Lectores.

Pablo Núñez, Luis (2010): El arte de las palabras: diccionarios e imprenta en el Siglo de Oro, Mérida, Editora Regional de Extremadura.

Peeters-Fontainas, Jean F. (1965): Bibliographie des impressions espagnoles des Pays-Bas méridionaux, Nieuwkoop, B. de Graaf.

Rodrigo Mora, María José (2015): "La pluralidad linguística en la Península Ibérica según la Gramática de la lengua vulgar de España (1559)", Confluenze: Rivista di Studi Iberoamericani, 7/2, pp. 71-83.

Roldán, Antonio (1977): Vtil y breue institvtion para aprender los principios y fundamentos de la lengua hespañola, Lovaina 1555, edición facsimilar con estudio e índice de ..., Madrid, Consejo Superior de Investigaciones Científicas.

Schmid, Beatrice (1998): “«Es cosa dura hazer novedad». Nebrija y la ortografía castellana”, en Maria Antonietta Terzoni (ed.), Colloquium zu Ehren von Germán Colón. Acta - Atti - Actes - Actas- Actes, Basel, UniBasel, pp. 59-67.

Swiggers, Pierre (2006): "El foco 'belga': Las gramáticas españolas de Lovaina (1555, 1559)”, en José J. Gómez Asencio (dir.), El castellano y su codificación gramatical I. De 1492 (A. de Nebrija) a 1611 (John Sanford), Burgos, Instituto de la Lengua castellano y leonés, pp. 161-213.

Truman, Ronald W. (1979): "Fadrique Furió Ceriol's Return to Spain from the Netherlands in 1564: Further Information on its Circumstances", Bibliothèque d'Humanisme et Renaissance, 41/2, pp. 359-366.

Wilke, Carsten L. (1996): "Bononia en su contexto histórico", en Fadrique Furió Ceriol, Obra completa I. El consejo y consejeros del príncipe. Bononia, València, CNRS, Universitat de València, UNESCO, Alfons el Magnànim, pp. 145-214.

Fecha de recepción: 28 de mayo de 2019

Fecha de aceptación: 25 de septiembre de 2019 